\title{
Soft-sediment benthic community structure in a coral reef lagoon - the prominence of spatial heterogeneity and 'spot endemism'
}

\author{
T. A. Schlacher ${ }^{1, *}$, P. Newell ${ }^{1}$, J. Clavier ${ }^{2}$, M. A. Schlacher-Hoenlinger ${ }^{3}$, \\ C. Chevillon ${ }^{4}$, J. Britton ${ }^{5}$ \\ 'Department of Biology, University of the South Pacific, Suva, Fiji \\ ${ }^{2}$ Centre ORSTOM, BP 70, F-29280 Plouzané, France \\ ${ }^{3}$ Institut für Medizinische Biologie, University of Vienna, Schwarzspanierstr. 17, A-1090 Vienna, Austria \\ ${ }^{4}$ Centre ORSTOM, BP A5, Nouméa, New Caledonia \\ ${ }^{5}$ GIS Unit, Department of Geography, University of the South Pacific, Suva, Fiji
}

\begin{abstract}
An encompassing view of coral reef ecosystems needs to extend beyond the prominent and attractive hard substrata to include soft-sediment habitats associated with the reefs. Focusing on the soft-sediment assemblages within the lagoon of the Great Astrolabe Reef (Fiji), we quantified patterns, clines and variability of community structure across space and evaluated models for marine biodiversity conservation based on the spatial distribution and rarity of benthic species. Water depth sampled ranged from 17 to $42 \mathrm{~m}$ over a spatial sampling scale of $18 \times 11 \mathrm{~km}$ with 25 localities on average $2.4 \mathrm{~km}$ apart. Both plant diversity and biomass were poor predictors of zoobenthic diversity. In contrast to the commonly held view that sediment characteristics are the prime factors in structuring benthic assemblages, spatial variability of the benthos was overriding the generally weak relationships between sedimentary features and the biota. High spatial heterogeneity in community structure is a key feature of the benthic biota in the lagoon. Part of this pronounced spatial heterogeneity stems from the marked patchiness in individual species distributions, here operationally coined 'spot endemism'. Out of a total of 211 recorded taxa, $42 \%$ were rare, being restricted to a single site. No species' range spanned the entire lagoon; in fact, the maximum species range was 16 out of 25 sites sampled. Furthermore, the number of taxa common to any 2 localities was not strongly linked to spatial distance. with adjoining sites having no more taxa in common than more distant localities. The commonness of rarity, prevalence of highly compressed species' range sizes, and patchiness in benthic diversity all combine to have profound implications for conservation strategies of these marine benthic habitats.
\end{abstract}

KEY WORDS: Soft-sediment communities · Marine biodiversity · Coral reefs · Conservation

\section{INTRODUCTION}

Marine biodiversity often peaks around coral reefs (Reaka-Kudla 1996, Gray 1997). Of the total described 274000 marine species, roughly one-third (93000) are known from coral reefs. The number (including presently undescribed forms) of species associated with warm-water coralline structures is, however, conserva-

- Present address: Faculty of Science, Sunshine Coast University, Locked Bag no. 4, Maroochydore DC, Queensland 4558. Australia.E-mail: tschlach@scuc.edu.au tively estimated to be at least 950000 (Reaka-Kudla 1996). The diverse coral reefs provide a range of ecosystem services to coastal populations (e.g. Done et al. 1996), which is most significant in small island states whose economies often lack other natural commodities and resource bases.

The use of hotspots in setting conservation priorities continues to have a major influence on conservation planning (Mittermeier et al. 1998, Reid 1998), and coral reefs are often identified as hotspots of global biodiversity (McAllister et al. 1994). Application of hotspot (defined by species richness) information in conservation 


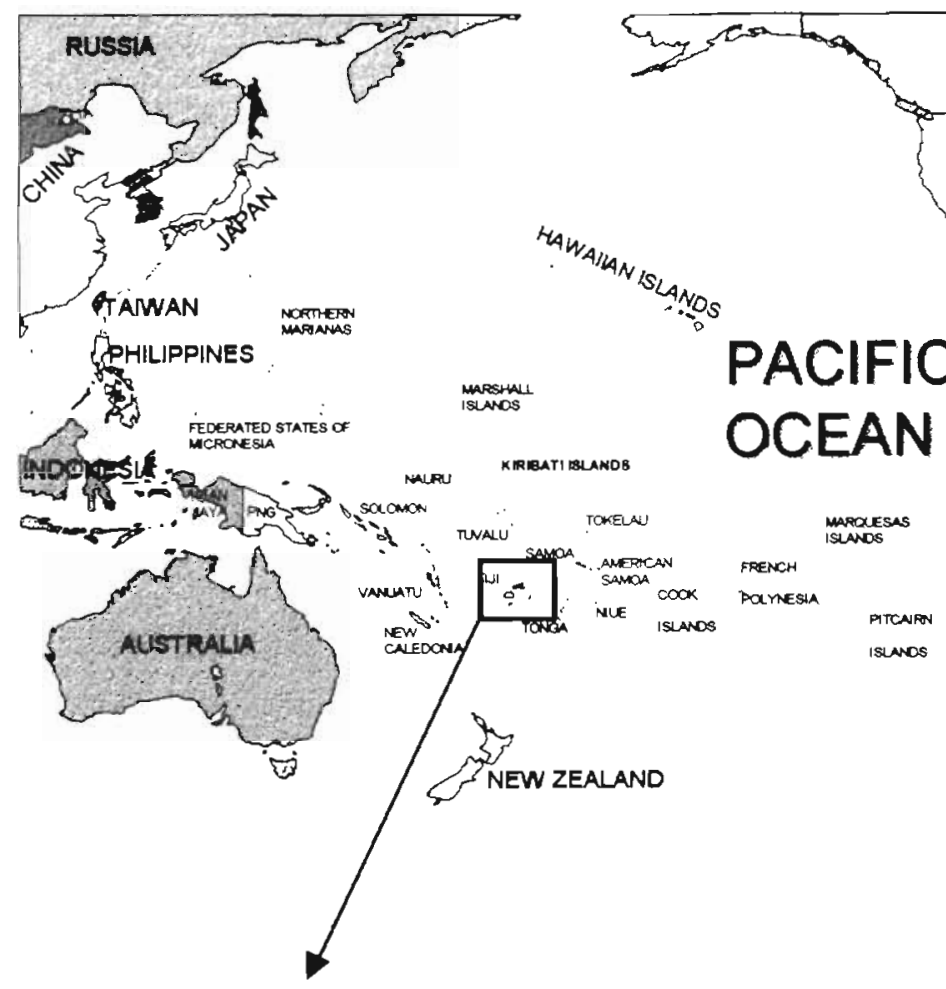

EASTER

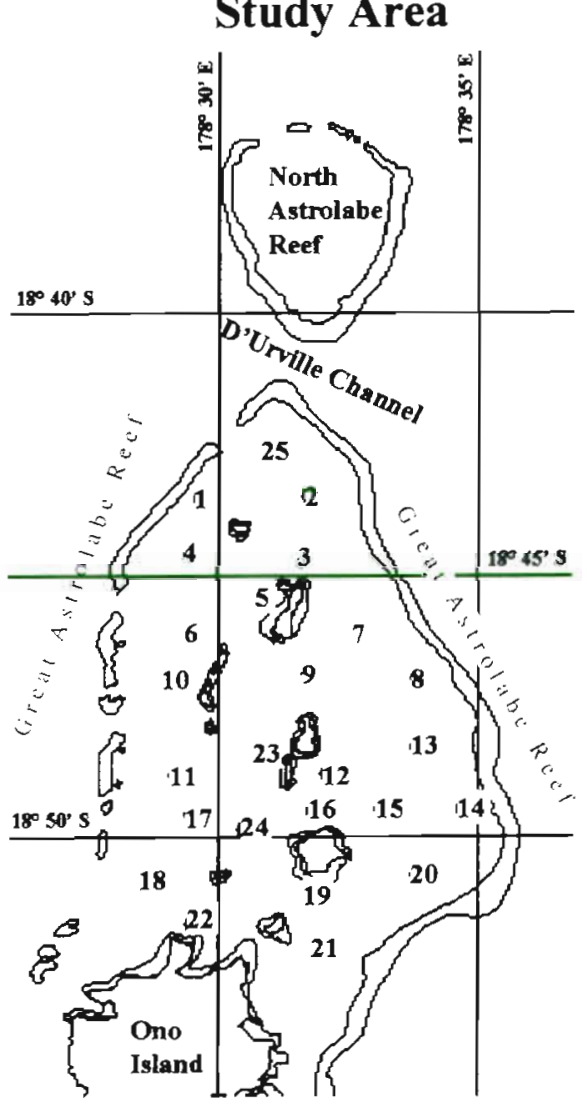

Fig. 1. Geographic postion of the Fi.ji archipelago and map of the study area showing position of sampling sites surveyed for softsediment benthos within the lagoon of the Great Astrolabe Reef 
generally relies on a positive relationship between conserving overall diversity and conserving endemic and rare species. If, however, areas of high species richness fail to coincide with those rich in endemic and rare species (Prendergast et al, 1993), this approach may have shortcomings.

The paradigm of coral reefs as self-sufficient ecosystems is increasingly giving way to models which incorporate trans-boundary fluxes (Hatcher 1997). Sedimentary habitats, which cover extensive areas adjacent to the prominent coralline structures, are arguably important compartments in such cross-habitat exchanges of material and energy. This appreciation of a more integrative approach to coral reef studies is, however, rarely matched by real-world data situations. One of the hallmarks of coral reef ecology is a dominance of hard-substrate studies sharply contrasted by limited information on sedimentary biotopes in the tropics (but see Hansen et al. 1987, 1992, Chardy \& Clavier 1988, Riddle et al. 1990, Garrigue 1995). In addition, tropical soft-bottom benthic systems differ in several aspects (e.g. stress levels, predation intensity, prevalence of opportunistic species, types of microbial carbon processing) from temperate counterparts (for reviews see Alongi 1989a, b, 1990).

Starting from a general conceptual framework that recognises the functional importance of all habitat types in coral reef systems (sensu Hatcher 1997), we targeted 3 key areas in this study: (1) levels of spatial heterogeneity and patterns of community structure of the soft-sediment benthos, (2) distribution of species' range sizes and their relationship to local population density and body mass, and (3) spatial distribution of species diversity and the scaling of species turnover. We end with an evaluation of the performance of conservation strategies for local marine biodiversity. In this final step the information gained on the presence of different community types, levels of species richness and the number of rare species are used as criteria for site selection.

\section{METHODS}

Field sampling. Field methods used to obtain the data set on the soft-sediment benthos analysed by us are described in detail by Clavier et al. (1996). This paper also provides a detailed site $x$ species matrix of abundance and biomass values. In brief, 25 sites ranging in depth from 17 to $42 \mathrm{~m}$ were sampled in April 1994 in the lagoon of the Great Astrolabe Reef (Fig. 1, Table 1). Total sampling coverage spanned ca $18 \mathrm{~km}$ in a north-south direction, and ca $11 \mathrm{~km}$ from east to west; mean distance between adjoining sites was $2.4 \mathrm{~km}$. At

Table 1 . Summary of physical and sedimentary characteristics and biomass values for macrophytes and macrofauna at 25 sites at which benthic communities were surveyed within the lagoon of the Great Astrolabe Reef (cf. Fig. 1)

\begin{tabular}{|c|c|c|c|c|c|c|}
\hline \multirow[t]{2}{*}{ Site } & \multirow[t]{2}{*}{ Depth $(\mathrm{m})$} & \multicolumn{3}{|c|}{ Sediment parameters } & \multicolumn{2}{|c|}{ Biomass (AFDW $\mathrm{g} \mathrm{m}^{-2}$ ) } \\
\hline & & $\%$ mud content & Median phi $(\phi)$ & Texture & Phytobenthos & Zoobenthos \\
\hline 1 & 31 & 16.99 & 2.60 & Slightly gravelly muddy sand & 0.00 & 1.08 \\
\hline 2 & 28 & 41.56 & 3.68 & Slightly gravelly muddy sand & 0.00 & 1.15 \\
\hline 3 & 22 & 4.71 & 1.31 & Slightly gravelly sand & 3.09 & 1.82 \\
\hline 4 & 39 & 74.26 & 4.33 & Slightly gravelly sandy mud & 0.00 & 2.30 \\
\hline 5 & 17 & 3.77 & 1.12 & Gravelly sand & 0.00 & 1.60 \\
\hline 6 & 38 & 32.94 & 2.47 & Slightly gravelly muddy sand & 0.01 & 0.87 \\
\hline 7 & 43 & 68.92 & 4.27 & Slightly gravelly sandy mud & 0.00 & 1.46 \\
\hline 8 & 37 & 56.36 & 4.11 & Slightly gravelly sandy mud & 0.00 & 3.02 \\
\hline 9 & 35 & 30.96 & 2.17 & Gravelly muddy sand & 0.00 & 2.56 \\
\hline 10 & 37 & 45.31 & 3.65 & Slightly gravelly muddy sand & 0.00 & 1.98 \\
\hline 11 & 39 & 44.01 & 3.36 & Slightly gravelly muddy sand & 0.00 & 9.32 \\
\hline 12 & 29 & 28.76 & 1.83 & Gravelly muddy sand & 0.49 & 9.11 \\
\hline 13 & 34 & 54.31 & 4.08 & Gravelly mud & 0.01 & 1.16 \\
\hline 14 & 27 & 42.64 & 3.66 & Gravelly muddy sand & 1.55 & 1.76 \\
\hline 15 & 29 & 5.83 & 1.07 & Gravelly sand & 0.21 & 2.02 \\
\hline 16 & 32 & 42.88 & 3.61 & Gravelly muddy sand & 1.12 & 0.88 \\
\hline 17 & 34 & 16.06 & 0.94 & Gravelly muddy sand & 0.06 & 0.65 \\
\hline 18 & 34 & 9.48 & 1.14 & Gravelly muddy sand & 0.00 & 1.37 \\
\hline 19 & 31 & 59.87 & 4.16 & Slightly gravelly sandy mud & 0.77 & 2.68 \\
\hline 20 & 34 & 44.7 & 3.76 & Slightly gravelly muddy sand & 0.00 & 0.49 \\
\hline 21 & 30 & 10.82 & -0.03 & Muddy sandy gravel & 0.16 & 2.67 \\
\hline 22 & 36 & 74.6 & 4.33 & Slightly gravelly sandy mud & 0.00 & 0.71 \\
\hline 23 & 31 & 59.98 & 4.17 & Gravelly mud & 14.94 & 13.63 \\
\hline 24 & 32 & 14.78 & 0.20 & Gravelly muddy sand & 23.32 & 8.57 \\
\hline 25 & 31 & 9.58 & 2.10 & Slightly gravelly muddy sand & 0.08 & 0.38 \\
\hline Lagoon & 32.4 & 35.76 & 2.72 & Gravelly muddy sand & 1.83 & 2.93 \\
\hline
\end{tabular}


each site, 10 replicates of $0.1 \mathrm{~m}^{2}$ each were taken with a Smith McIntyre grab. All animals and plants retained on a sieve of $2 \mathrm{~mm}$ mesh size were enumerated and biomass values determined both in terms of dry weight $\left(60^{\circ} \mathrm{C}\right.$ until constant) and ash-free dry weight $\left(550^{\circ} \mathrm{C}\right.$ for $3 \mathrm{~h}$ ). Sediments within the lagoon consist predominately of gravelly muddy sands, but there is considerable variation in mud content (range: 4 to $75 \%$ ) and median particle size (phi [ $\phi]$ range: -0.03 to 4.33) among sites (Table 1).

Data analysis. Multivariate analyses follows the strategy originally outlined by Field et al. (1982) and detailed in Clarke (1993). In brief, biotic and abiotic data matrices are handled separately. Classification (group average clustering) and ordinations (non-metric multidimensional scaling) of biotic data are based on Bray Curtis dissimilarity coefficients calculated in this study from untransformed biomass (ash-free dry weight) values. To link the observed biotic structure to measured environmental variables we employed the BIO-ENV methodology of Clarke \& Ainsworth (1993). In this procedure the among-sample similarity matrix for the biota is constructed only once, but the equivalent triangular matrix for the environmental data is computed for all possible combinations of measured environmental variables. The subset of environmental data which 'best explains' the biotic structure is taken as that combination of environmental variables whose triangular matrix shows the highest harmonic rank correlation (i.e. weighted Spearman coefficient) with the similarity matrix constructed from the species-biomass data. All the above procedures are implemented in the PRIMER (Plymouth Routines in Marine Ecological Research) package which was used for all computations.

Randomisation of site sequences for the calculation of species accumulation curves was done using the 'BioDiversity' software. The programme is available as freeware from the Natural History Museum, London (http://www.nhm.ac.uk/zoology/bdpro/). For calculations of density-range size relationships, local species abundance values were averaged across space including only non-zero counts. Exclusion of sites not actually occupied by a species from the total pool avoids artefactual deflation of mean density estimates (Lacy \& Bock 1986). Labelling of species restricted to a single site ('uniques') and species represented by a single individual in a sample ('singletons') follows the terminology of Colwell \& Coddington (1994). Similarly, 'doubletons' are species represented by exactly 2 individuals in a sample, and 'duplicates' are species occurring at 2 localities only.

As univariate measures of diversity we used the 0th, 1st and 2nd order of Hill's (1973) series of diversity numbers:

$$
N A=\sum_{i=1}^{S}\left(p_{i}\right)^{1 /(1-A)}
$$

NA is the Ath 'order' of diversity and $p_{l}$ is the proportional abundance of the $i$ th species. $N O$ is simply $S$ or the total number of species (species richness), $N 1=$ $\mathrm{e}^{H \prime}$, where $H^{\prime}$ is Shannon's index; and $N 2=\lambda^{-1}$, where $\lambda$ is Simpson's index. Over the very widely used Shannon and Simpson indices these measures have the appeal of having the same units - effective species numbers' (Hill 1973). Explicitly, N1 measures the number of abundant species, while $N 2$ is the number of very abundant species; $N O$ is the number of all species regardless of abundance (Ludwigs \& Reynolds 1988, see also Magurran 1988).

\section{RESULTS}

\section{Basic community properties}

Soft-sediment assemblages of the Great Astrolabe Reef lagoon are numerically dominated by surface deposit feeders, which account for $43 \%$ of total macrobenthic density (Fig. 2A). Their endobenthic counterparts (i.e. deposit swallowers) attain densities of only one-third ( $13 \%$ mean proportional abundance) of surface-active detritus feeders (Fig. 2A). Suspension feeders and predators are about equally abundant, each group comprising 20 to $24 \%$ of total heterotrophic density (Fig. 2A). Interguild differences in relative contribution to benthic standing stock are smoothed by inclusion of plant biomass (Fig. 2B). Biomass distribution among functional groups becomes even, with each guild comprising roughly one-fifth of total standing stock (Fig. 2B).

Annelids were the most abundant taxon recorded (mean numerical dominance $33 \%$ ), followed by bivalves $(22 \%)$ and crustaceans $(19 \%)$; the combined density of these 3 taxa makes up about three-quarters of the total abundance in the benthos (Fig. 2C). Numerical dominance of annelids was, however, not matched by relative biomass of this group - annelids ranked well behind macrophytes, crustaceans, echinoderms and molluscs (Fig. 2D). Greater individual body mass combined with moderate densities make bivalves the most important contributor to benthic biomass in the lagoon (Fig. 2D).

Distribution of species among individuals followed a log-series model, with a dominance of species of very low population sizes, and only a few abundant species (Fig. 3). In fact, save for 2 macrofaunal species, mean densities at a site comprised a single individual. Such species-abundance models may, however, be a function of spatial integration (or the lack thereof) of spe- 

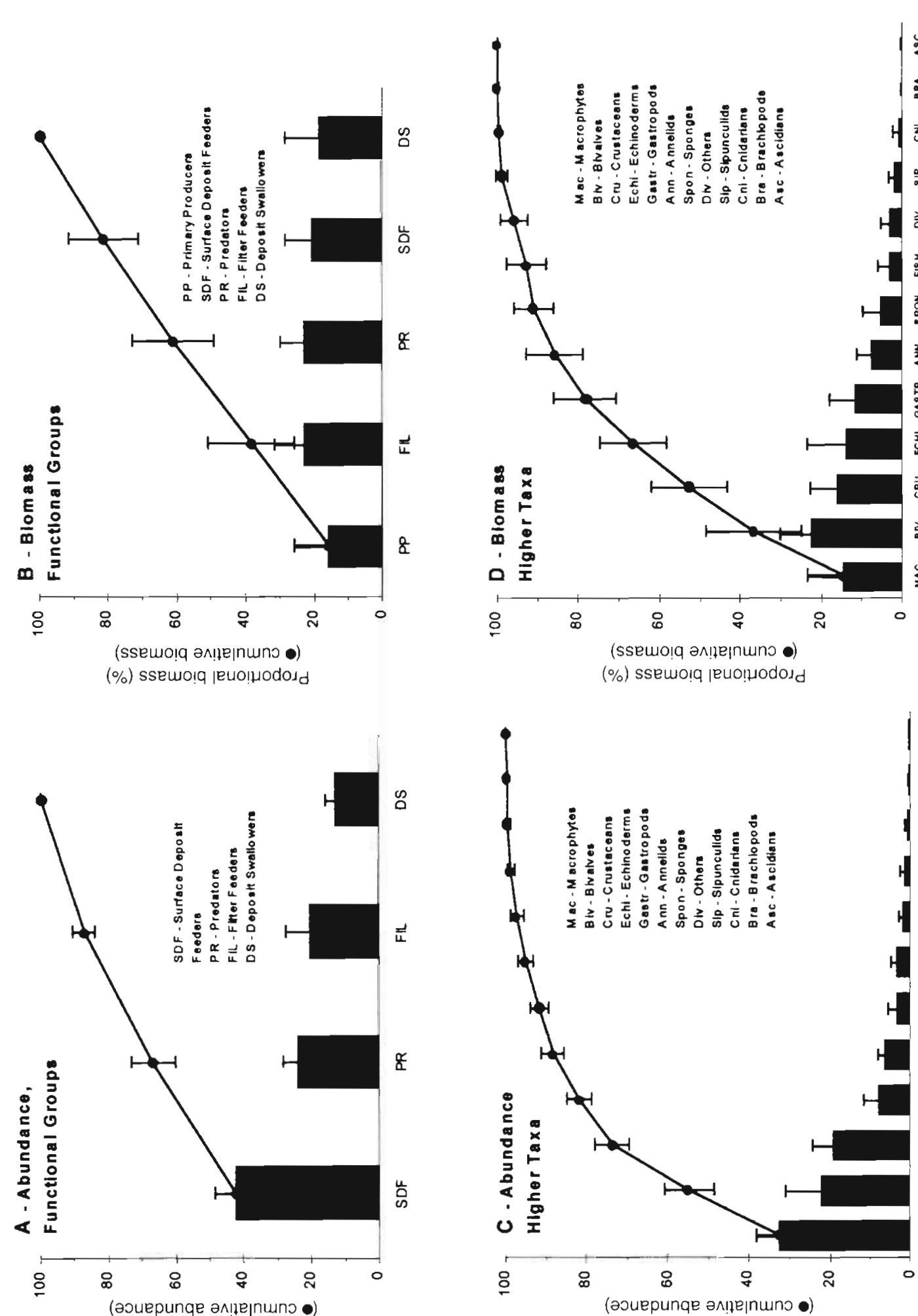

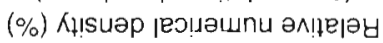

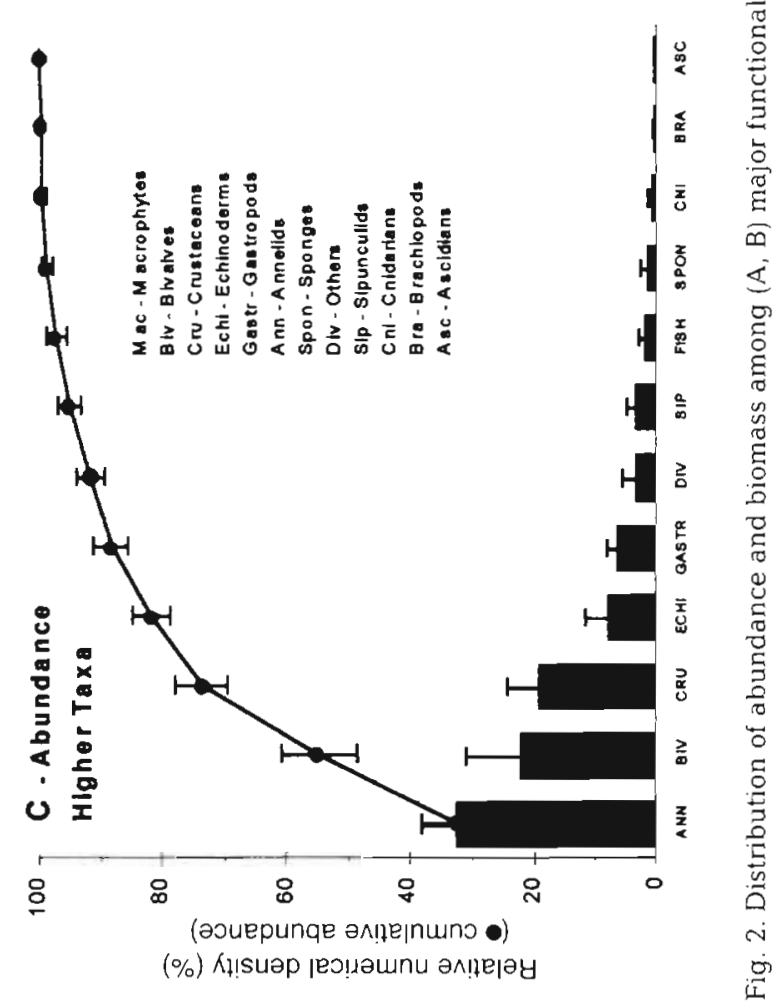




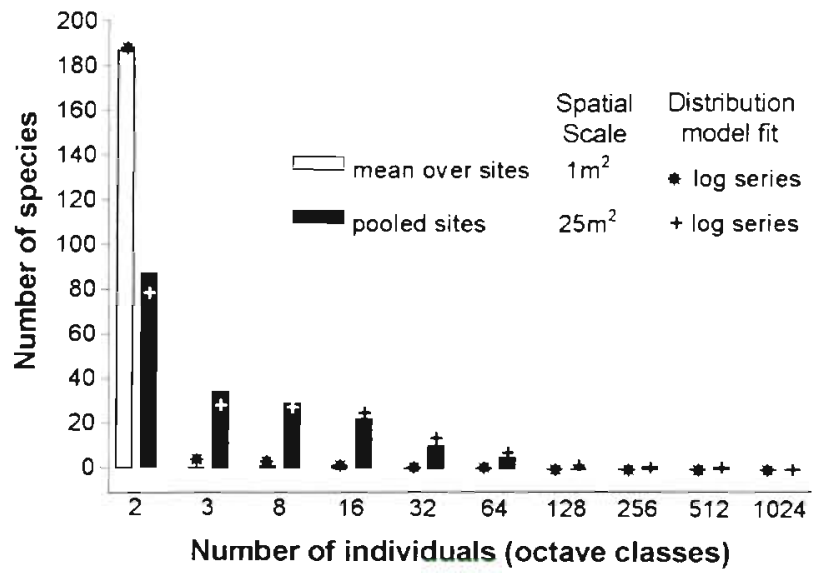

Fig. 3. Species abundance plot at 2 different spatial scales. Solid bars denote the number of species per octave class when individuals are pooled over all sites sampled $(n=25)$ while open bars denote the number of species when mean densities per site are used. Superimposed point symbols show values of log-series fits. (*) Fitted values for means over all sites, $(+)$ fitted values for pooled sites (goodness of fit test: pooled: $\chi^{2}=5.83, p>0.3$; means: $\chi^{2}=4.55, p>0.03$ )

cies population estimates. Combining population estimates over the entire lagoon (i.e. 25 sites of $1 \mathrm{~m}^{2}$ each) results in a more equitable distribution of species among abundance classes, but the log-series pattern still prevails (Fig. 3). Indubitably, spatial scale is a powerful determinant of distribution models, but, in the case of the soft-sediment communities studied here, any resulting differences are a matter of degree not of kind - the commonness of rarity is real.

Table 2. Interspecific relationships between range size (proportion of sites occupied) and abundance and body size within taxonomic groups and guilds. Measure of correlation is Spearman rank correlation with significant $\left(\mathrm{p}_{(2)}<0.05\right)$ coefficients in bold face

\begin{tabular}{|c|c|c|c|c|c|}
\hline & \multirow[t]{2}{*}{$\mathrm{n}$} & \multicolumn{2}{|c|}{$\begin{array}{l}\text { Local density vs } \\
\text { range size }\end{array}$} & \multicolumn{2}{|c|}{$\begin{array}{c}\text { Body size vs } \\
\text { range size }\end{array}$} \\
\hline & & $r_{s}$ & $\mathrm{p}_{(2)}$ & $\mathrm{r}_{\mathrm{s}}$ & $p_{(2)}$ \\
\hline \multicolumn{6}{|l|}{ Higher taxa } \\
\hline Annelids & 51 & -0.15 & 0.30 & -0.23 & 0.11 \\
\hline Bivalves & 23 & 0.45 & 0.03 & -0.11 & 0.63 \\
\hline Gastropods & 30 & 0.40 & 0.02 & 0.15 & 0.42 \\
\hline Crustaceans & 45 & 0.51 & $<0.01$ & -0.14 & 0.35 \\
\hline Erhinoderms & 13 & 0.88 & $<0.01$ & -0.34 & 0.25 \\
\hline Fish & 6 & 0.70 & 0.14 & -0.93 & 0.02 \\
\hline \multicolumn{6}{|l|}{ Guilds } \\
\hline Predators & 78 & 0.50 & $<0.01$ & -0.02 & 0.89 \\
\hline Filter feeders & 32 & 0.46 & $<0.01$ & -0.15 & 0.41 \\
\hline Deposit swallowers & 17 & 0.18 & 0.48 & 0.04 & 0.89 \\
\hline $\begin{array}{l}\text { Surtace deposit } \\
\text { feeders }\end{array}$ & 62 & 0.53 & $<0.01$ & -0.33 & 0.01 \\
\hline
\end{tabular}

\section{Biotic assemblages in space-lack of spatial homogeneity}

Community structure showed a low degree of conformity across space. Five distinct benthic assemblages are present in the soft-sediment habitats of the lagoon (Fig. 4). Community membership (sensu site affinity) varies from 2 (cluster I) to 6 (cluster IV) localities, but is not a uniform function of spatial position of individual sites within the lagoon.

Lack of correlation between spatial position and community membership gives rise to a spatial pattern of community structure that is characterised by: (1) greatly varying distributional ranges of individual assemblages, (2) overlap of community boundaries, and (3) nested spatial arrangement in which most assemblages are subsets of more widely distributed assemblages. An important distinction must be drawn between spatial nesting (sensu feature 3 above) and biotic overlap. Assemblages which are situated within the boundaries of other assemblages have distinct biotic structures - they simply occupy a similar area but differ in species composition and relative biomass. Four sites $(13,16,17,25)$ could not be reliably classified and are treated as 'outliers' in all further analysis.

No clear relationship could be found between environmental variables and biotic assemblages. Correlations between individual environmental factors (water depth, distance from reef, mean $\phi$, \% silt and clay, kurtosis, skewness, sorting) and intersite similarities of community structure (BIOENV procedure, see Clarke \& Ainsworth 1993) are weak (range of $r=-0.11$ to -0.20 ). The subset of environmental variables which best explains biotic patterns includes sorting and skewness of sediments; it performs marginally better $(r=0.27)$ than single factors. It is probable that environmental factors other than those measured may well have a stronger deterministic influence on community structure.

\section{Species' range sizes}

Range sizes of soft-sediment taxa are strongly compressed. No single species spans the entire lagoon. In fact, the maximum range is 16 sites out of a total of 25 localities sampled, and only 2 species, out of a total of 211 recorded, occupy this 'maximum' range (Fig. 5). Conversely, 88 species (42\%) are restricted to a single site, highlighting the high degree of 'spot endemism' in the community. Moreover, $80 \%$ of the fauna occurs at no more than 4 sites (Fig. 5).

For most higher taxa (except annelids and fish) range size is positively correlated with local abundance (Table 2). Similarly, when species are grouped 


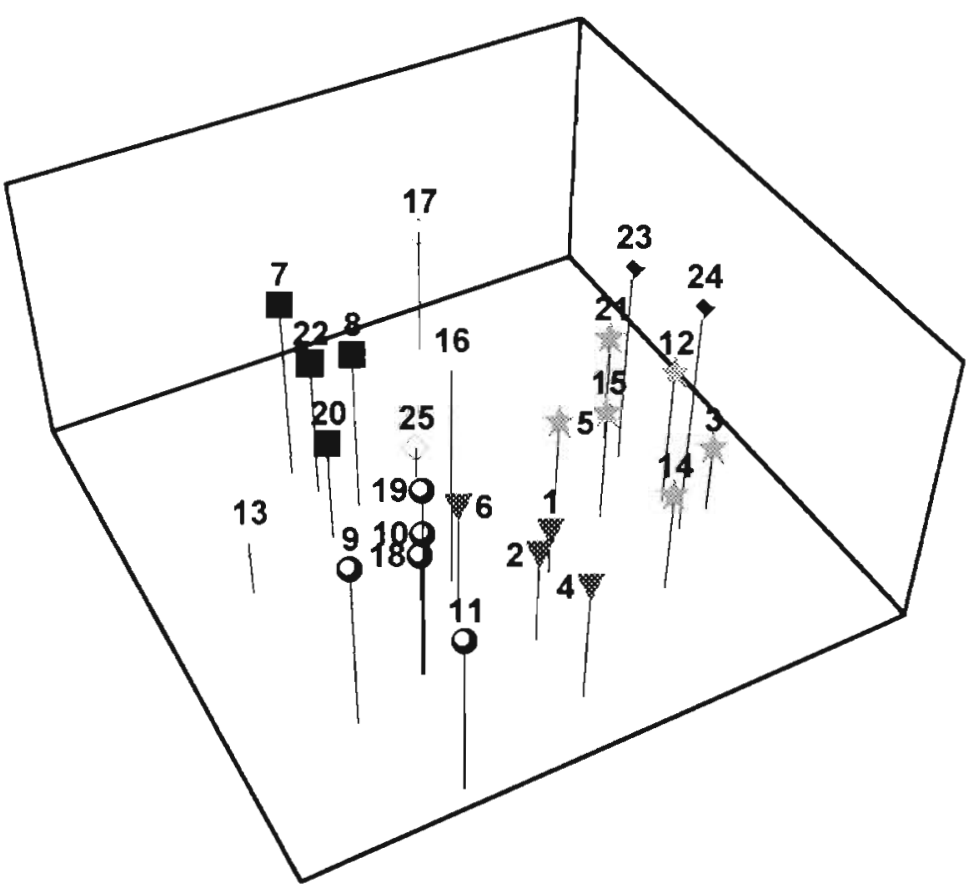

Fig. 4. Ordination of sampling sites and spatial representation of resulting community types. Analysis based on untransformed biomass data (AFDW) using the Bray-Curtis similarity coefficients and non-metric multidimensional scaling (NMDS, final stress in $3 \mathrm{~d}=0.14 \mathrm{~J}$. Different symbols in both the ordination diagram and the map representation denote sites with different community composition as defined by clustering and ordination

according to feeding mode, the positive relationship between range size and local abundance prevails (save for deposit swallowers, Table 2). By contrast, body size is a poor predictor of range size, with large species being generally no more widespread than small ones (Table 2); only fish and surface deposit feeders show a negative correlation between range size and body size.

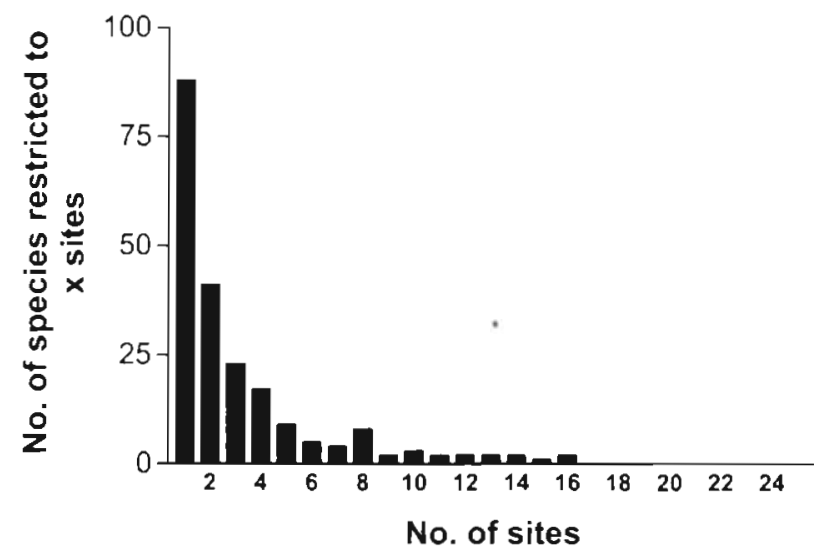

Fig. 5. Distribution of range sizes among benthic species Range size is the number of sites occupied by a species out of a total of 25 localities sampled (cf. Fig. 1)

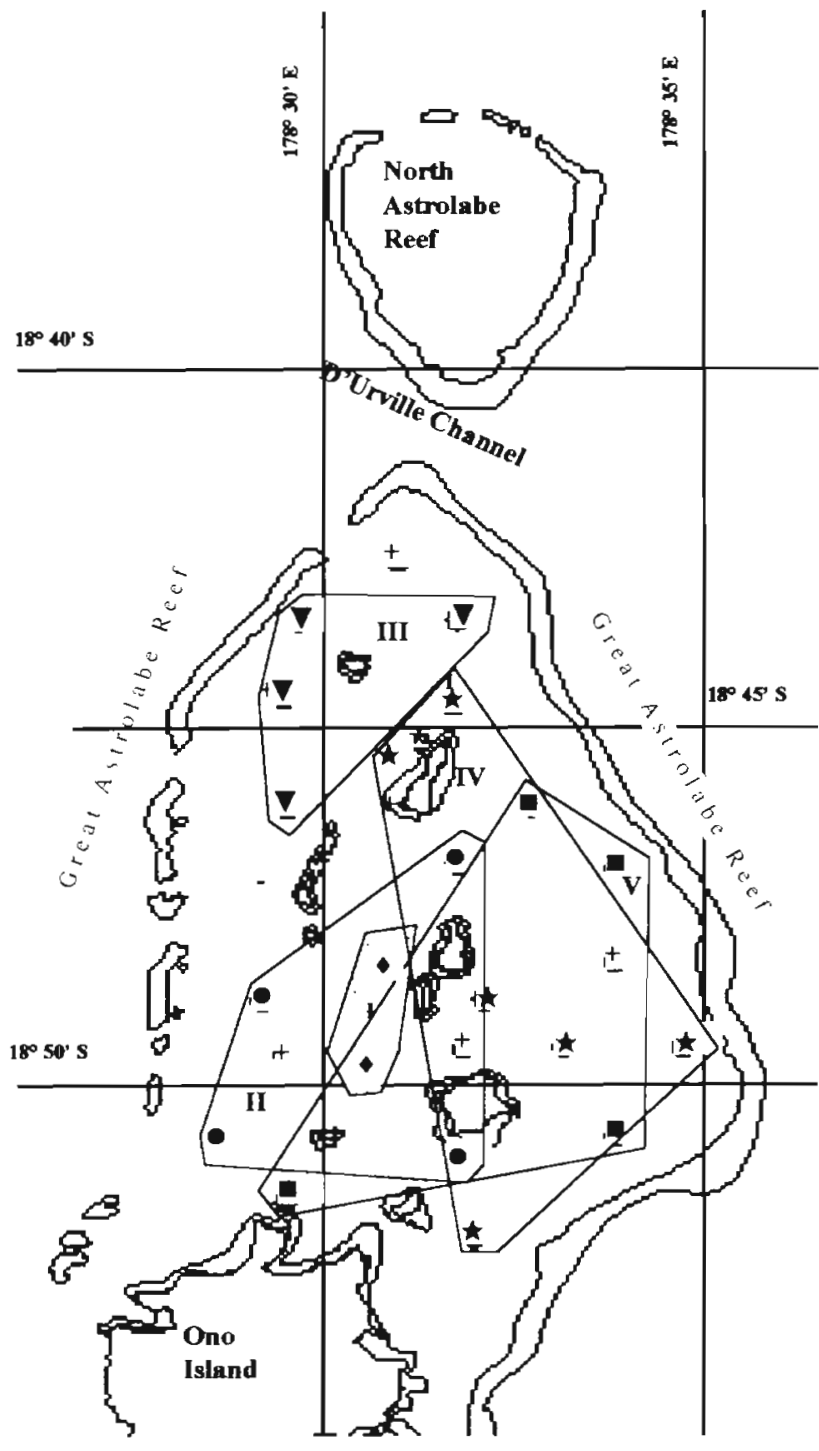

Two corollaries emerge from this: (1) species which are locally rare (rarity defined by intensity) are also spatially rare (rarity defined by prevalence), and (2) rarity status is generally independent of body size.

\section{Biotic diversity}

Species richness of benthic taxa peaks in the centre of the lagoon, both for algae (Fig. 6A) and macrofauna (Fig. 6B). This pattern is reflected in algal diversity, again being highest in the central part of the lagoon (Fig. 6C). By contrast, macrofaunal diversity shows a more equitable spatial pattern, with a centre located towards the northwest sector of the lagoon (Fig. 6D).

Neither local species richness nor diversity bears any strong relationship to environmental variables measured (Table 3). The only significant correlation is a 


\section{Biotic Richness}

No. of Algae Taxa

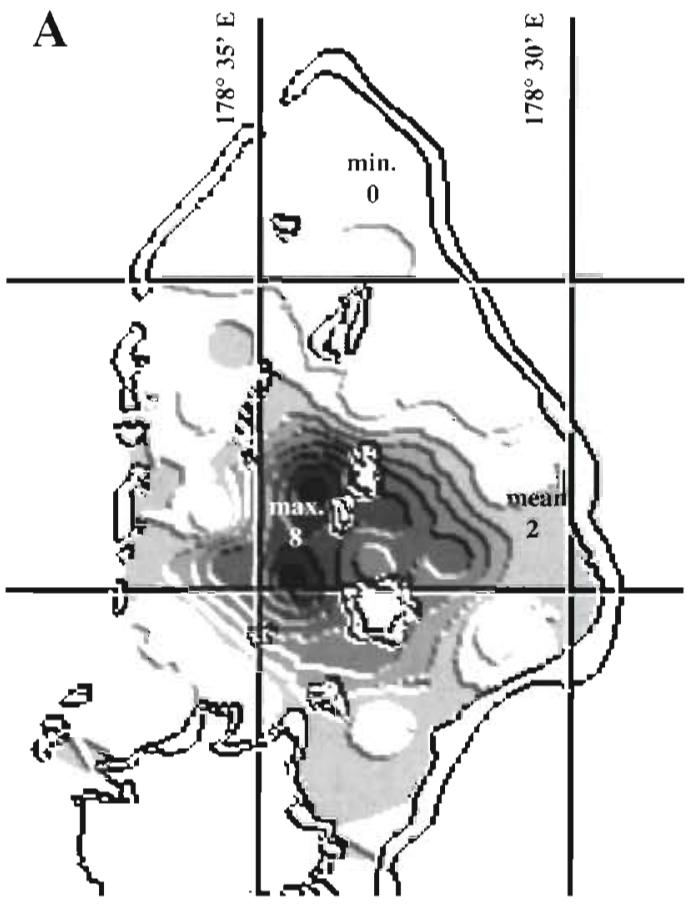

No. of Macrofauna Taxa

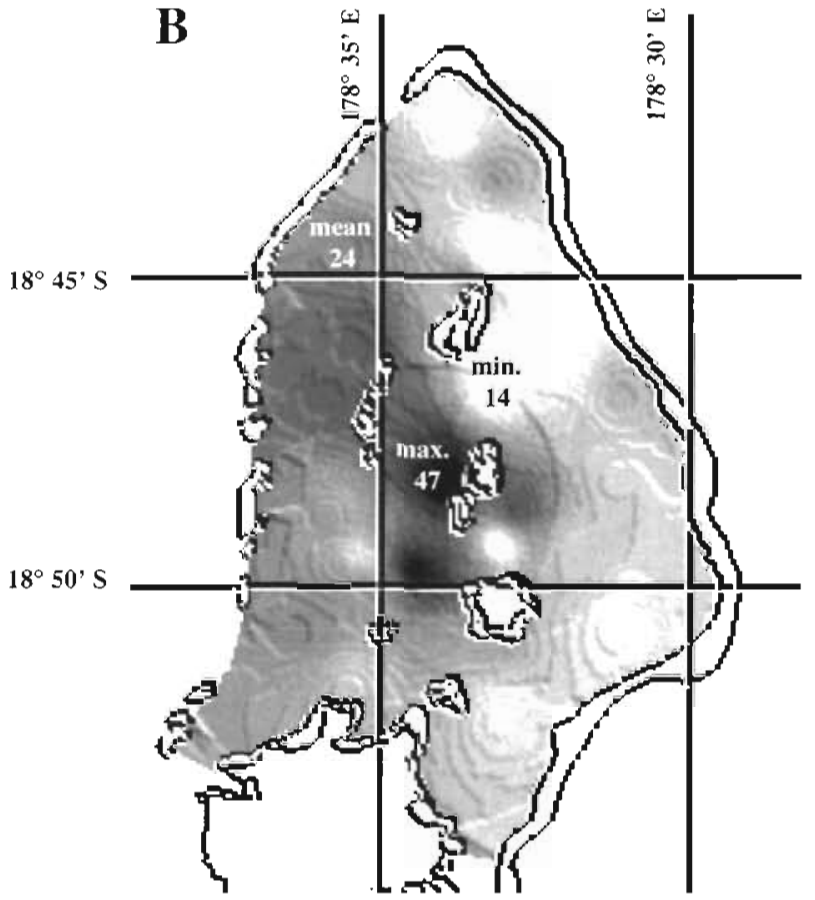

\section{Biotic Diversity}

Hill's N2 - Phytobenthos

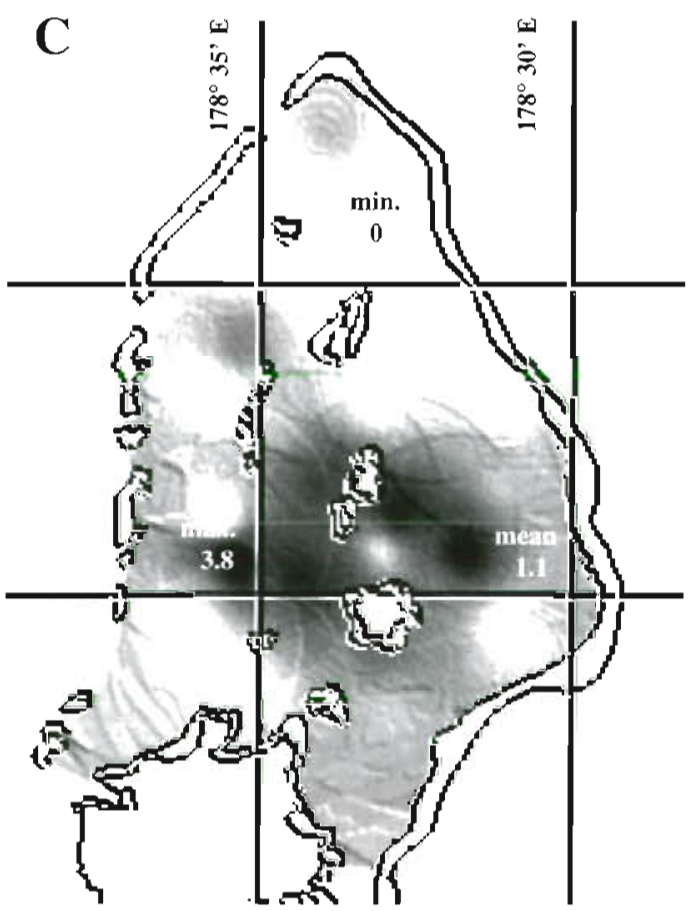

Hill's N2 Macrobenthos

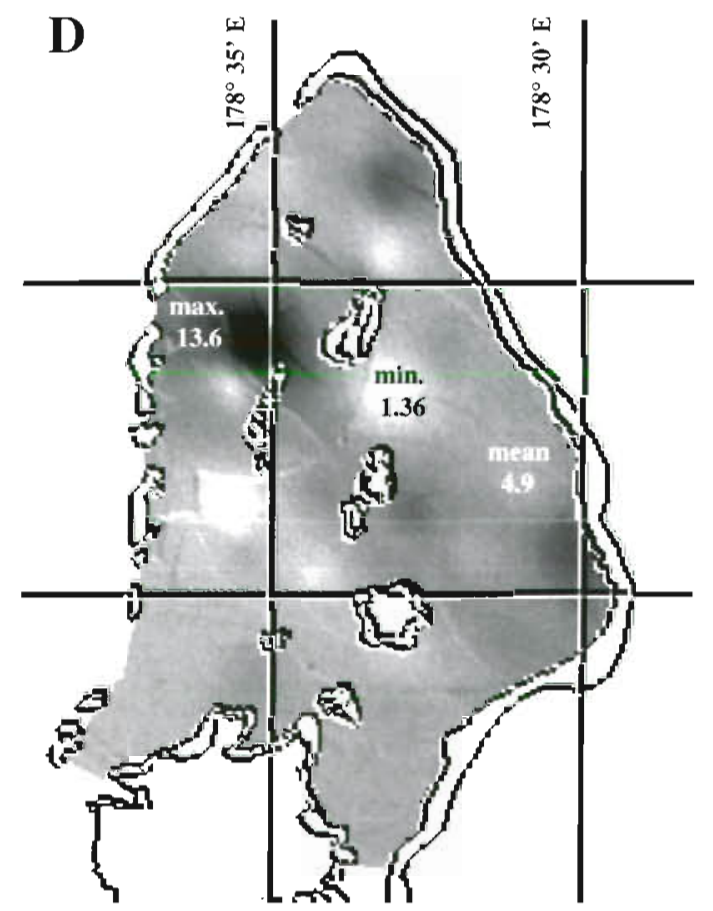

Fig. 6. Spatial distribution of biotic richness and diversity within the soft-sediment habitats of the Great Astrolabe Reef lagoon. (A, B) Measure of richness is the total number of benthic macroalgae taxa and zoobenthos taxa; (C, D) diversity measured by Hill's $N 2$ 
Table 3. Spearman rank correlations between biotic diversity and selected environmental variables $\left(" p_{(2)}\left\langle 0.05\right.\right.$, all others $\left.p_{(2)}\right\rangle$ $0.05 \mathrm{i}$ for all correlations $=25$ ). $N O$ is simply $S$ or the total number of species (species richness), $N 1=\mathrm{e}^{H^{\prime \prime}}$, where $H^{\prime}$ is Shannon's index; and $N 2=\lambda^{-1}$, where $\lambda$ is Simpson's index

\begin{tabular}{|c|c|c|c|c|}
\hline & Water depth & Distance from reef & Sediment (mean $\phi$ ) & Sediment $(\%$ silt and clay $)$ \\
\hline \multicolumn{5}{|l|}{ Phytobenthos } \\
\hline Richness: Hill's NO & -0.39 & -0.12 & -0.38 & -0.20 \\
\hline Diversity: Hill's N1 & -0.38 & -0.08 & -0.39 & -0.24 \\
\hline Diversity: Hill's N2 & -0.38 & -0.07 & $-0.40^{\circ}$ & -0.25 \\
\hline \multicolumn{5}{|l|}{ Zoobenthos } \\
\hline Richness: Hill's NO & 0.13 & -0.10 & -0.02 & 0.16 \\
\hline Diversity: Hill's N1 & -0.17 & -0.30 & 0.20 & 0.19 \\
\hline Diversity: Hill's N2 & -0.19 & -0.17 & 0.23 & 0.17 \\
\hline
\end{tabular}

weak decline in algae diversity (as measured by Hill's N2) with finer sediments (Table 3). Higher plant diversity and richness do not translate into higher animal richness or diversity (max. $r_{s}=0.19, p_{(2)}=0.36$ ).

Species turnover among habitats is high and independent of spatial scale (Fig. 7). $\beta$-Diversity (measured as absolute species complementarity between all pairwise combinations of sites) scales only weakly $\left(\mathrm{r}_{\mathrm{s}}=\right.$ $-0.18, \mathrm{p}_{(2)}=0.002, \mathrm{n}=300$ ) with intersite distance. Thus, $\beta$-diversity is not a uniform function of spatial arrangement of habitats. Adjacent sites (nearest neighbours) do on average not share significantly more species than site pairs further apart (Fig. 7). These results are not confounded by the measure of $\beta$-diversity employed. Standardising for species richness in pairwise combinations (Dice coefficient) does not affect the independence of $\beta$-diversity from spatial distance between localities: species turnover is not significantly correlated to intersite distance $\left(\mathrm{r}_{\mathrm{s}}=-0.11, \mathrm{p}_{(2)}=0.06, \mathrm{n}=300\right)$.

\section{DISCUSSION}

\section{Range-abundance relationships- sampling property or real pattern?}

Positive interspecific abundance-range size relationships are a broad statistical generalisation which applies to a multitude of taxonomic assemblages, a variety of habitat types, and a host of geographic regions (Brown 1984). Our data do not differ in that, and species of low abundance also have compressed range sizes (Table 2). Despite their almost universal validity, the processes driving these pervasive relationships are not
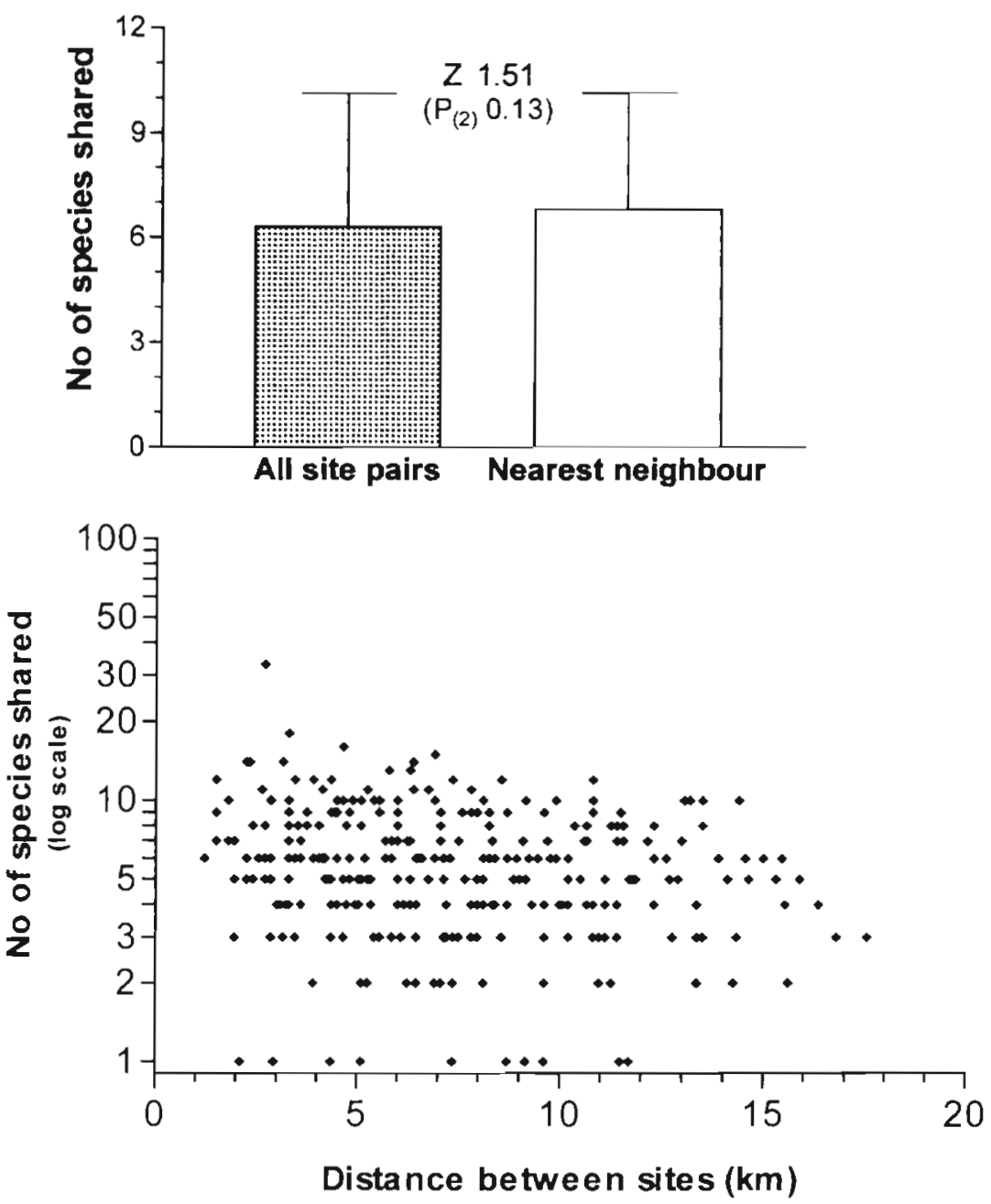

Fig. 7. Species turnover across sites. $\beta$-Diversity is assessed by the number of species common to 2 sites for all pairwise permutations of sites over the total area sampled. Species turnover is only weakly correlated to interhabitat distance $\left(\mathrm{r}_{\mathrm{s}}=-0.18, \mathrm{p}_{(2)}=0.002\right)$, and does not differ significantly between the smallest spatial scale investigated (nearest neighbour) and the full set of pairwise site combinations 


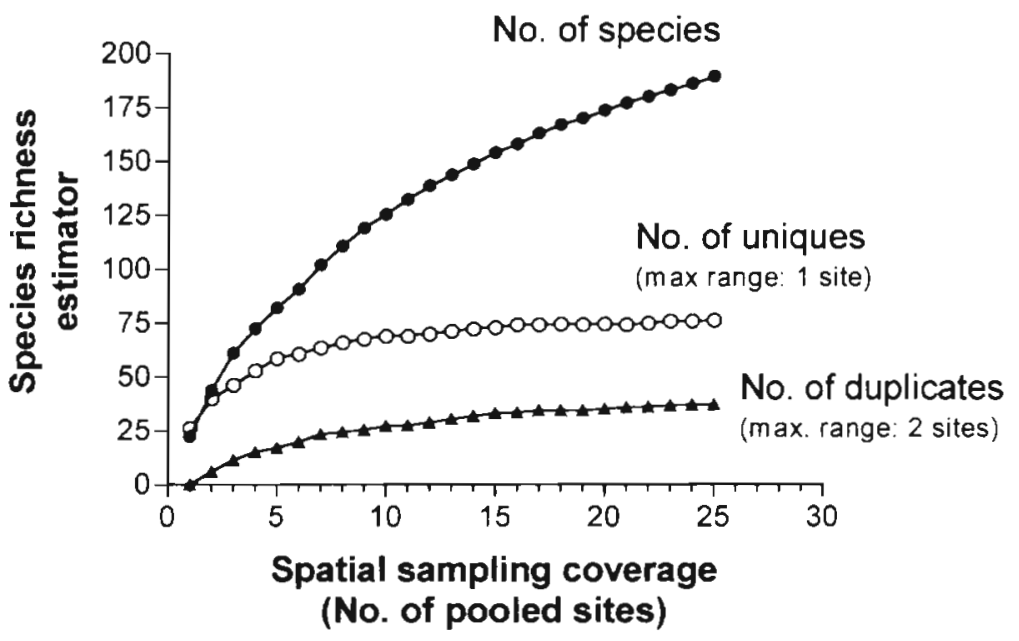

Fig. 8. Species accumulation curves for zoobenthos. Estimators of richness are the total number of all species ( $)$, the number of species restricted to a single site (uniques, 0 ), and number of species found at exactly 2 sites only (duplicates, $\mathbf{\Delta}$ ). Plotted values are means of 25 random reshuffles of sample order was adequately estimated with the employed collecting protocol (Fig. 8). Thus, it is common species which are added with increasing sampling coverage rather than restricted-range species.

This confers confidence to several prominent distribution patterns found for the benthic assemblages of the Great Astrolabe Reef lagoon: (1) prevalence of species with low local densities (Fig. 3), (2) highly compressed distribution ranges with most species being 'spot endemics' (Fig. 5), (3) overlap of community boundaries in the form of a nested pattern of assemblages in space (Fig. 4), (4) high species turnover among habitats combined with independence of $\beta$-diversity and spatial scale (Fig. 7), and (5) positive interspecific abundance-range size relationships (Table 2). clear and no single proposed mechanism has emerged to explain all cases convincingly (Gaston et al. 1997b).

The most parsimonious explanation for this pattern centres on sampling artefacts. Essentially, insufficient sampling intensity underestimates the range sizes of species that occur at low local densities even though their real distributional limits coincide with those of more abundant species (Hanski 1991, Hanski et al. 1993). The only honest remedy to separate artefactual from real mechanisms is to increase sampling intensity at the local (within site) scale, until accumulation curves for species approach asymptotes. This might not always be a practical strategy in marine benthic situations in which rare species are often continuously added with increasing sample size, thus coming fullcircle (Schlacher \& Wooldridge 1996a). Our sampling strategy consisted of 10 replicate samples at each site. which is at the high end of sampling coverage usually employed in marine benthic surveys. Also, compelling evidence comes from numerous studies in which confounding factors can reliably be discounted, showing that positive abundance-range size relationships are emergent properties of ecological systems (Gaston et al. $1997 \mathrm{a}$ ).

The above argument is logically closely related to reliably estimating 'spot endemism' (i.e. species restricted to a single site), which simply represent range-size estimates at the smallest spatial scale possible. In this case an approximation of sampling performance is possible, because insufficient sampling coverage is predicted to artificially inflate estimates of locally restricted species. This was not the case in this study. Although estimates of total species richness show little sign of stabilising towards asymptotic values, the number of 'spot endemics'

\section{Implications for conservation strategies}

While these community properties are of fundamental interest to extract processes and mechanisms causing any such pattern, they also provide a set of challenges for the design of effective conservation strategies. Indubitably, there is much to be gained from proper designs over arbitrary definitions of conservation areas (Lawton et al. 1994). The question arises, however, as to what design criteria to employ or what weight to assign to different ecological properties.

Rare species present a special and often problematic case in that their relationship to overall site diversity is far from uniform across habitat types, taxonomic groups, or geographic regions (Gentry 1992, Lawton et al. 1994, Sanderson 1996). Most importantly, lack of correspondence between hotspots of diversity and hotspots of rarity across different taxa (Prendergast et al. 1993) challenges the utility of hotspots in setting conservation priorities.

What exactly constitutes 'rarity' is another vexing problem, and rarity comes in at least 7 different forms (Rabinowitz 1981, Gaston 1994). Here we define rare species exclusively on the grounds of their distributional range - Gaston's (1991) 'area of occupancy' - irrespective of local intensity and population size. Out of the total macrofaunal pool of 189 species recorded in this study, 63 species were found at a single site ('uniques' sensu Colwell \& Coddington 1994) and 7 species occurred at exactly 2 sites only ('duplicates'). This group of 70 species, which comprises a significant fraction of the benthos $(37 \%)$, was considered rare and treated sepa- 
rately in all further analysis. Thus, in the present usage, rare species are 'spot endemics' but may or may not be locally abundant.

\section{Do 'hotspot' models work?}

Intuitively appealing and widely applied are strategies that identify conservation areas of high biotic diversity. Most weight is placed on sites that have species numbers above the regional or national average and resulting conservation policies consequently assign high priority to such 'hotspots'. The central tenet is to capture as much as possible of the regional diversity in smaller spatial subsets. Although the term 'biodiversity hotspot' was originally coined to signify areas which contain large numbers of endemic and threatened species, it is now most commonly used for regions of high species numbers (Reid 1998). In this paper we follow the most widely applied usage and define hotspots solely in terms of species richness.

Applying the classical 'hotspot' approach to the soft-bottom communities of the Great Astrolabe Reef was the first step in devising a strategy for future identification of conservation areas within the lagoon. The ultimate success of any design in conserving biotic diversity can only be unequivocally gauged by time-series studies - a requirement that is impossible to meet in the planning stages. As a proxy measure it is, however, sensible to measure the proportion of the local species pool-another proxy measure but this time for diversity - which can be captured at any given level of conservation effort. Conservation effort or intensity is taken as the number of sites to fall, in the future, under some form of conservation management or protection

The hotspot approach works well in capturing more species of the total local species pool for any given number of sites compared with simple random assignment of sites to conservation areas. This holds true for both rare species and the total species pool (Fig. 9). To conserve $75 \%$ of the macrobenthic species recorded in the lagoon requires putting the 10 most species-rich sites under some form of conservation management. This compares with 13 sites following arbitrary choices of site assignment (note that $75 \%$ or any other proportion of the local species pool is not a criterion for ecosystem function or integrity but simply stands in for comparative purposes only). Considerably more sites (15) will have to be pro-
A - rare taxa

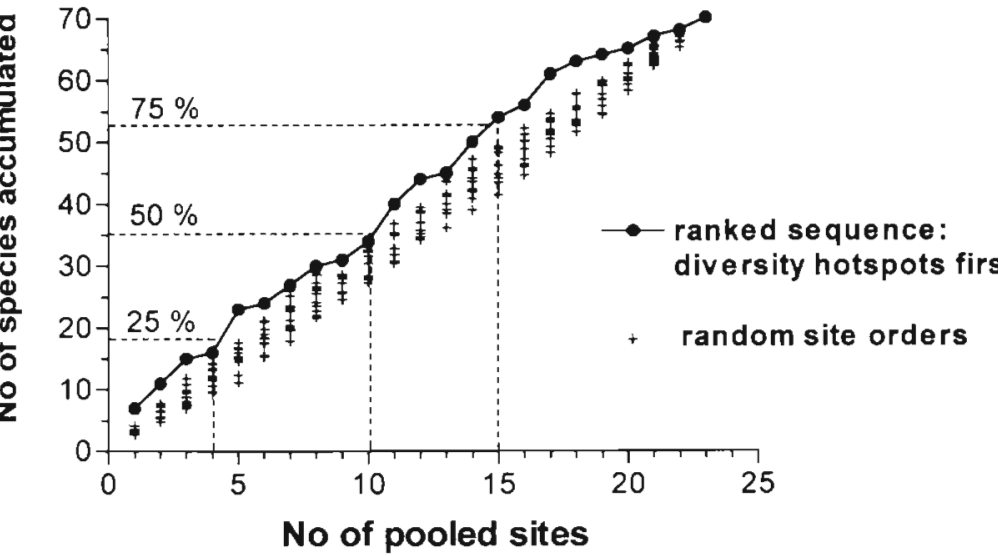

B - all zoobenthic taxa

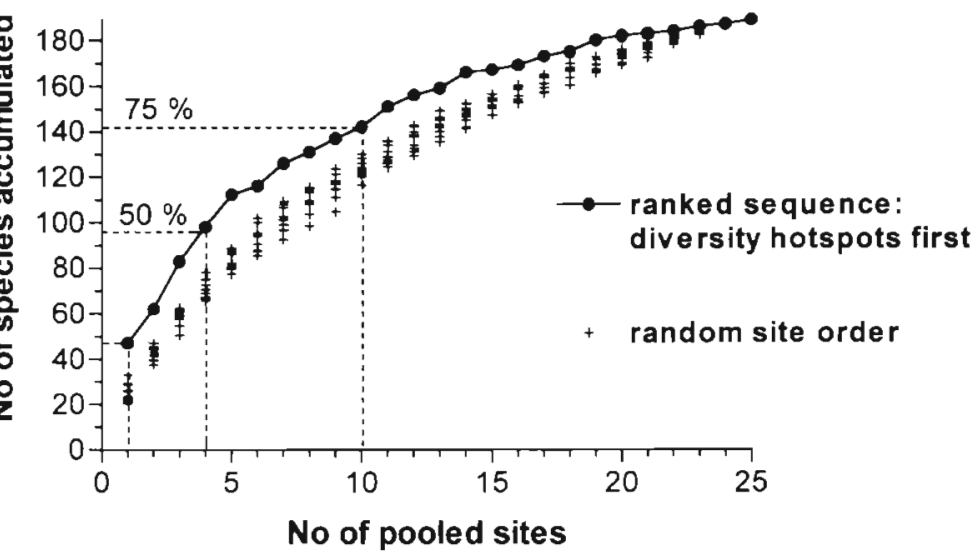

Fig. 9. Spatial scaling of zoobenthic species richness as a function of pooling procedure. Strategy 'hotspot' is a ranked sequence of pooling which progresses from sites with maximum species richness (hotspots) to speciespoorest localities. This is compared to a random (10 independent runs of 5 random reshuffles each) sequence of sites. (A) Criterion for rarity is the number of sites occupied, with 'rare' taxa in this analysis occupying 1 $(\mathrm{n}=63)$ or $2(\mathrm{n}=7)$ sites only

tected to capture the same fraction of rare species (Fig. 9A). Thus, conservation that is directed exclusively towards total species richness would miss a significant fraction of the less common species

\section{Incorporating rarity into richness hotspots}

Over the last years, conservation has shifted from rare species towards greater emphasis on conserving areas of high diversity (Lawton et al. 1994). This approach essentially relies on positive effects of overall diversity on conserving endemic and rare species. The assumption that areas of high species richness coincide with those rich in endemic and rare species does not always hold (Prendergast et al. 1993, but see Kerr 1997). The evi- 

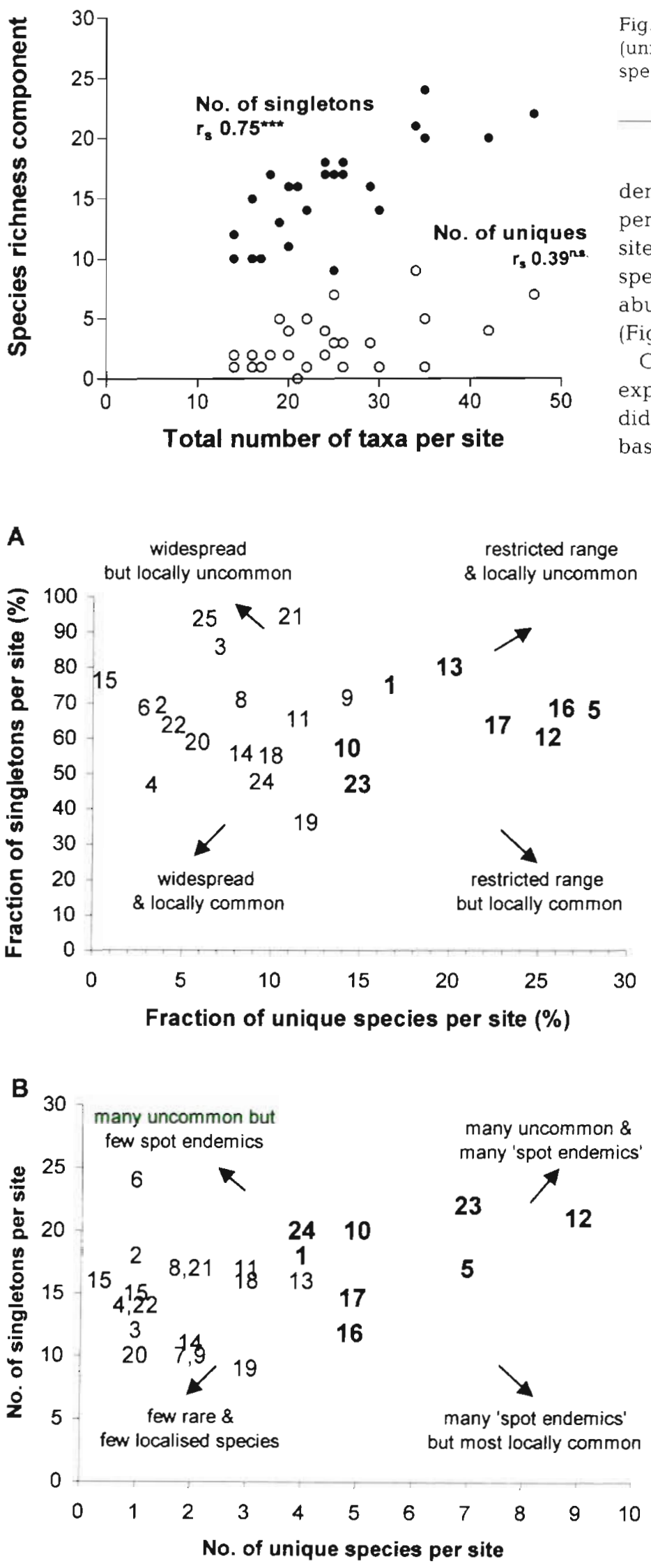

Fig. 10. Correlation between species richness and endemism (uniques, o) per site, and between species richness and species of the lowest possible population size per site (singletons, -). n.s.: $\mathrm{p}_{(2)}>0.05_{;}^{\star \star \star} \mathrm{p}<0.001$

dence from the benthic assemblages studied in this paper substantiates such arguments (Fig. 10): species-rich sites ('hotspots') do not contain significantly more rare species - they rather harbour more species of low local abundance but which are relatively widespread (Fig. 10).

Consequently, we shifted the focus to designs which explicitly take rarity into account. Identification of candidate sites for inclusion into conservation areas was based on 3 criteria: (1) number of unique species per site, (2) if tied ranks under rule 1: number of singletons per site, (3) if tied ranks under rule 2 : the proportion of unique species out of the total number of species present at a site. Such rarity scores can be graphically represented in RE (rarity-endemism) plots, either in the form of proportional site totals (Fig. 11A) or in absolute species numbers (Fig. 11B). Both display forms are complementary, emphasising distribution of rare species either within a locality (Fig. 11A) or among the entire suite of sites surveyed (Fig. 11B).

As might be expected from a strategy which has rarity explicitly built into its criteria, the 'spot endemism' approach performed well for rare taxa but worked equally well at the level of the total species pool (Fig. 12). In comparison to the hotspot (here defined solely by species richness) approach, significantly less spatial coverage was needed to achieve the same degree of conservation for rare species.

\section{Community structure or diversity - what defines ecosystem function?}

Both strategies outlined so far take no account of the existence of distinct assemblages. While the distinction between habitat, species and community conservation might be a tenuous one, defining conservation zones based on community membership can have

Fig. 11. Rarity-endemism (RE) plots for soft-sediment habitats of the Great Astrolabe Reef lagoon. The top $1 / 3$ of sites having the highest (A) proportion or (B) number of spot endemics and which harbour species of low population abundance are situated towards the upper right and are denoted by bold face 


\section{A - rare taxa}

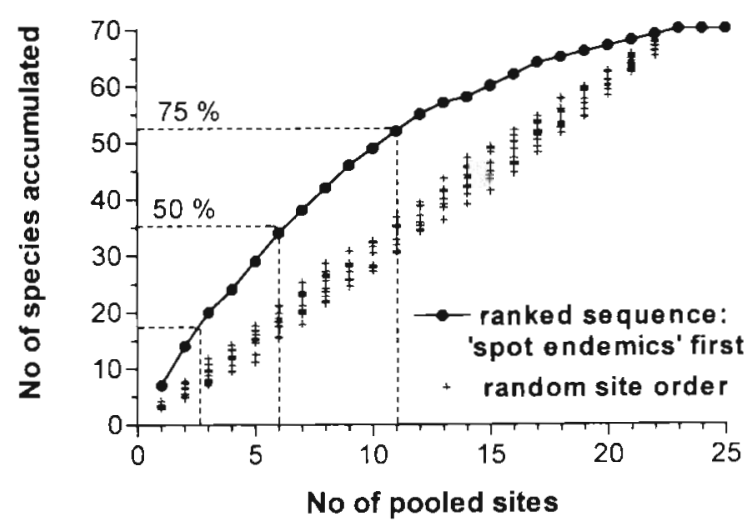

\section{B - all zoobenthic taxa}

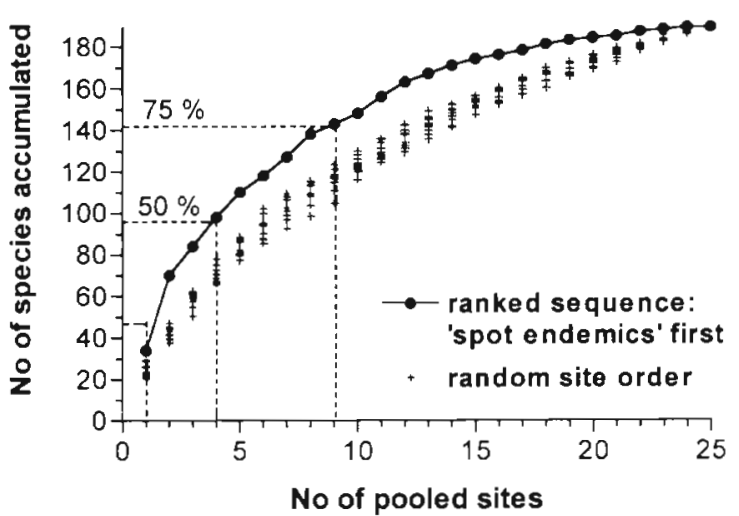

Fig. 12. Spatial scaling of species richness in the zoobenthos as a function of pooling procedure. Strategy 'spot endemics' is a ranked sequence of pooling which progresses from sites with the highest numbers of endemics to sites dominated by widely distributed species (cf. Fig. 11). This is compared to a random (10 independent runs of 5 random reshuffles each) sequence of sites. (A) Criterion for rarity is the number of sites occupied, with 'rare' taxa in this analysis occupying $1(n=63)$ or $2(n=7)$ sites only

attractive properties (Schlacher \& Wooldridge 1996b). Building on a community-wide level of organisation, however, invariably evokes arguments about the proper definition of a community, the functional and structural uniqueness of a defined assemblage, and the question of spatial and temporal coherence (Drake 1990, Samuels \& Drake 1997).

Losing sight of community properties in favour of maximising species richness carries its own set of problems (e.g. Gentry 1992). The question whether diversity is or is not related to ecosystem function is a contentious issue. To quote Grime (1997): 'so far, neither evolutionary theory nor empirical studies have presented convincing evidence that species diversity and ecosystem function are consistently and causally connected'. In sedimentary habitats, biodiversity per se

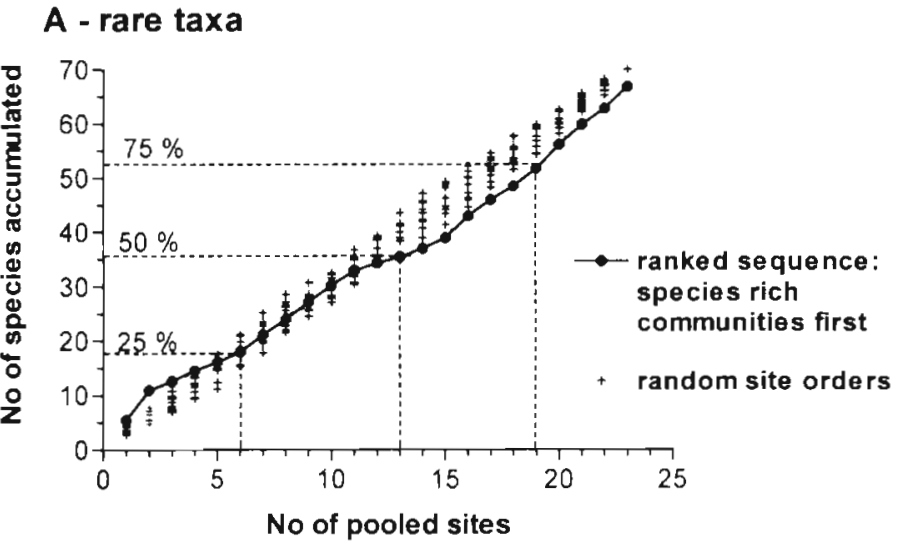

\section{$B$ - all zoobenthic taxa}

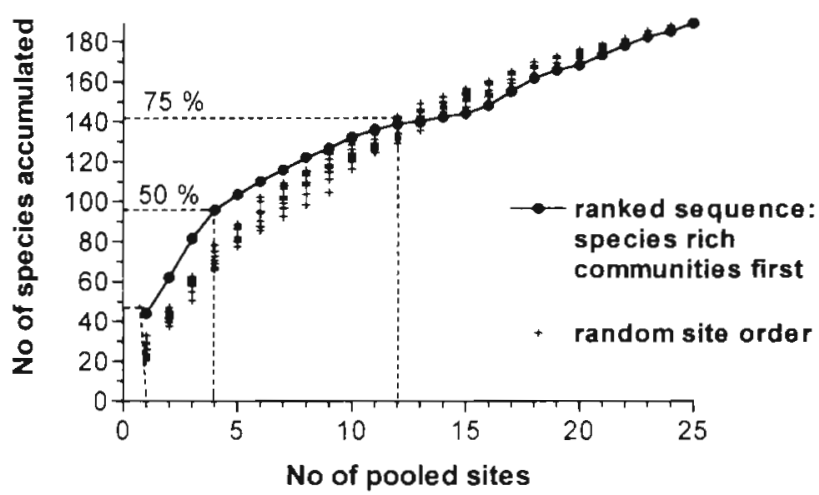

Fig. 13. Spatial scaling of species richness in the zoobenthos as a function of pooling procedure. Strategy 'community' is a ranked sequence of pooling which progresses from assemblages rich in species to assemblages of low diversity. This is compared to a random (10 independent runs of 5 random reshuffles each) sequence of sites. (A) Criterion for rarity is the number of sites occupied, with 'rare' taxa in this analysis occupying $1(\mathrm{n}=63)$ or $2(\mathrm{n}=7)$ sites only

may perhaps not necessarily be the major determinant of ecosystem processes (e.g. bentho-pelagic coupling, carbon and nutrient cycling, sediment stability and transport), but this may equally well reflect a lack of data on the functional complementarity (or overlap. sensu Peterson et al. 1998) and linkages of the component species (Snelgrove et al. 1997).

There is, however, a growing body of evidence which suggests (1) that community structure has important effects on ecosystem-level properties (e.g. Wardle et al. 1997), and (2) that functional diversity is more closely related to ecosystem processes than is mere species richness (Tilman et al. 1997). A recurring corollary of such findings is that ignoring species composition and managing for species diversity alone may be an unsatisfactory strategy if we wish to manage for critical ecosystem processes (Hooper \& Vitousek 1997). Thus, on balance it seems justified to make a case for inte- 


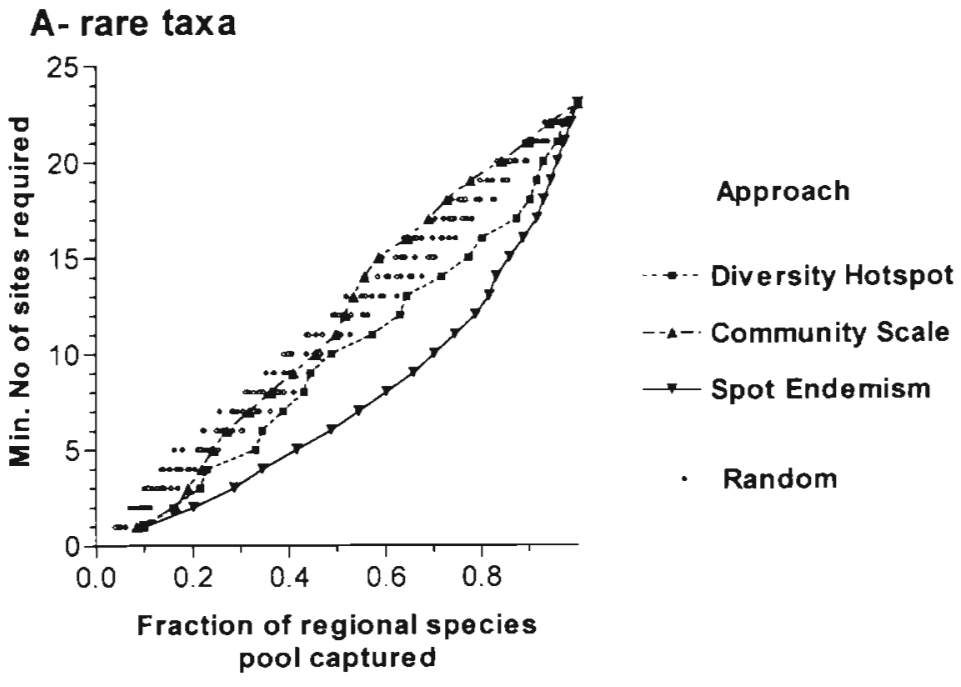

B- all zoobenthic taxa

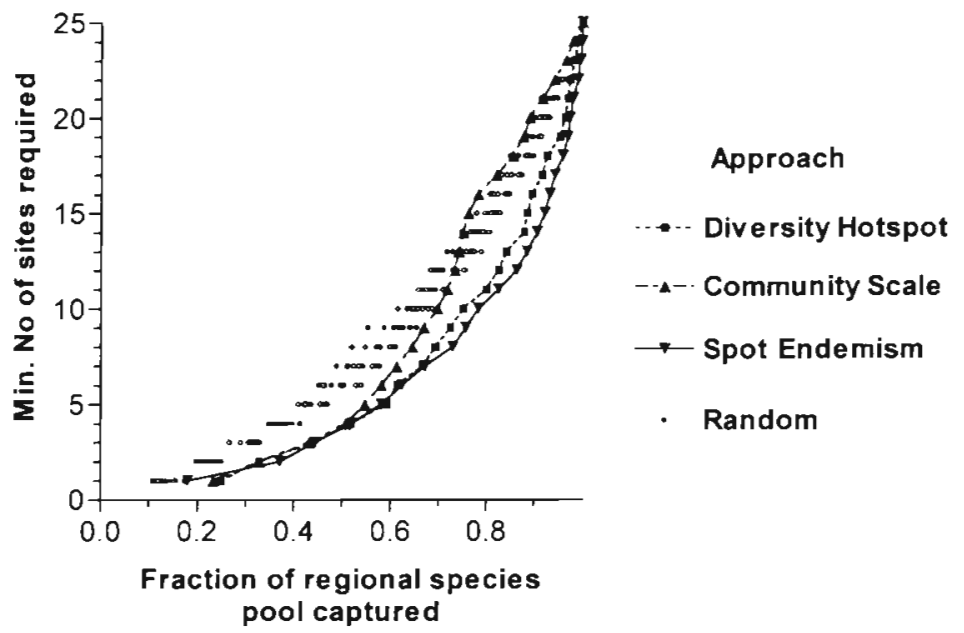

Fig. 14. Performance of 3 models used for setting priorities for site selection. 'Diversity hotspot' ranks species-rich sites high, irrespective of endemism or community membership (cf. Fig. 9), 'spot endemism' assigns top priority to sites with a high degree of endemism (cf. Fig 12), and 'community-scale' puts highly-diverse communities first (cf. Fig. 13)

grating community properties (or at least membership) into conservation designs

Adopting a community-wide approach in designing conservation strategies rests on assigning different priorities to different assemblages. This is not a straightforward matter and requires data on communityspecific rates of ecosystem processes (e.g. carbon and nutrient cycling), linkages to other ecosystem components (e.g. compartmentalised source-sink behaviour), and a good understanding of what exactly constitutes critical levels of ecosystem processes (sensu Hooper \& Vitousek 1997).

Soft-sediment benthic systems in the South Pacific are data-deficient in this respect. At present we there- fore feel that any 'functional' ranking of assemblages would rather reflect the researchers' intuition than objective criteria. Consequently, in the absence of data on community-specific rates of ecosystem function, we used mean species richness as the main criterion to rank different assemblages. Thus, species-rich communities are given top priority, while species-poor assemblages are treated as the least likely candidates for inclusion in future conservation areas. Group membership is always preserved (i.e. sites remain within a cluster as defined by classification and ordination analysis); sequential ordering of sites within groups is, however, random.

Remarkably, ranking of sites according to group membership and species richness resulted in species capture rates that were not superior to random site selection (Fig. 13). At low levels of spatial coverage (i.e. few sites), the community-wide approach performed better than random site assignments. This trend was, however, reversed at moderate levels of site pooling, at which random models achieved higher species capture rates than did community-scale strategies (Fig. 13).

\section{Which conservation model to follow?}

All 3 strategies outlined here are underpinned by different tenets about the type of ecosystem properties considered most significant for sustained viability. The distinction between 'hotspot' and 'rare' species conservation philosophies is rather a matter of degree than of kind. In the absence of compelling causal mechanisms which link overall diversity to rare species and ultimately ecosystem function (Grime 1997), it seems at least prudent to build criteria for less common species into the design process.

'Spot endemism' strategies perform better than simple hotspot approaches in conserving species with compressed ranges (Fig. 14A) and are equally effective when directed at the total species pool irrespective of the species' range sizes (Fig. 14B). The communitywide approach has perhaps the strongest theoretical basis (Diamond \& Case 1986) and empirical backing (Wardle et al. 1997), and may present an attractive avenue in real world situations (e.g. Schlacher \& Wooldridge 1996b). Yet, without detailed knowledge about the functional properties of assemblages it suf- 
fers from rigorous criteria against which to judge its conservation performance. This was the case in the present study and the resulting design is in fact a chimera of diversity and community properties. The consequence was a rather poor performance of the community-wide design compared with approaches focusing exclusively on diversity (Fig. 14)

There is of course much more to site selection and to the design of coherent and effective conservation programmes than mapping the distribution of species diversity and species' range sizes alone. The task is essentially of a multi-faceted nature and aspects which warrant inclusion may inter alia entail: (1) recognition of scale and hierarchical levels of ecological organisation (Norton \& Ulanowicz 1992), (2) inclusion of the fundamental ecological and evolutionary processes that produce patterns of biodiversity (Smith et al. 1993), (3) identification of extinction threats (Sisk et al. 1994), (4) pollution and its effects on coastal fisheries (Lundin \& Linden 1993), (5) assessment of the economic benefits gained from utilising biotic resources versus costs to society (Cesar et al. 1997), (6) the need to ensure that local people in developing countries derive tangible benefits from conservation programmes (Schlacher \& Wooldridge 1996c), (7) traditional marine tenure systems and historical fishing rights (these are particularly strongly developed and largely intact in Fiji; Jennings \& Polunin 1995), and (8) considerations of cultural and religious links to landscape features (Anon 1996).

While much of the ultimate success in conservation hinges on the balanced incorporation of social, economic and political goals, the starting point in any design process usually requires information on the distribution and abundance of the biota which are to be conserved. To this end, the case study presented by us provides a simple framework to gauge the potential conservation significance of particular localities. It makes, however, no predictions about the spatial arrangements of sites - save to some degree the community-wide strategy (cf. Fig. 4)-or about zoning decisions. We favour the 'spot endemism' approach and recommend RE (rarity-endemism) plots (Fig. 11) as a tool for making site assessments based on local degrees of species-range size distributions and abundance. This framework still awaits testing with data from other habitats, geographic regions and taxonomic assemblages.

\section{LITERATURE CITED}

Alongi DM (1989a) The role of soft-bottom benthic communities in tropical mangrove and coral reef ecosystems. Aquat Sci 1:243-280

Alongi DM (1989b) Ecology of tropical soft-bottom benthos: a review with emphasis on emerging concepts. Rev Biol
Trop 37:85-100

Alongi DM (1990) The ecology of tropical soft-bottom benthic ecosystems. Oceanogr Mar Biol Annu Rev 28:381-496

Anon (1996) Australia: state of the environment 1996-executive summary. CSIRO Publishing, Collingwood

Brown JH (1984) On the relationship between abundance and distribution of species. Am Nat 124:255-279

Cesar H, Lundin CG, Bettencourt S, Dixon J (1997) Indonesian coral reefs - an economic analysis of a precious but threatened resource. Ambio 26:345-350

Chardy P, Clavier J (1988) Biomass and trophic structure of the macrobenthos in the south-west lagoon of New Caledonia. Mar Biol 99:195-202

Clarke KR (1993) Non-parametric multivariate analyses of changes in community structure. Aust $\mathrm{J}$ Ecol 18: $117-143$

Clarke KR, Ainsworth M (1993) A method of linking multivariate community structure to environmental variables. Mar Ecol Prog Ser 92:205-219

Clavier J, Newell P, Garrigue C, Richer de Forges B, Di Matteo A (1996) Soft substrate macrobenthos of Fiji's Great Astrolabe Reef lagoon. List of taxons, densities and their biomass. Notes Doc Océanogr 1996:17-46

Colwell RK, Coddington JA (1994) Estimating terrestrial biodiversity through extrapolation. Phil Trans R Soc Lond B 345:101-118

Diamond J, Case TJ (1986) Community ecology. Harper \& Row, New York

Done TJ, Ogden JC, Wiebe WJ, Rosen BR (1996) Biodiversity and ecosystem function of coral reefs. In: Mooney HA, Cushman JH, Medina E. Sala OE, Schulze ED (eds) Functional roles of biodiversity: a global perspective. John Wiley \& Sons, New York, p 394-427

Drake JA (1990) Communities as assembled structures: do rules govern patterns? Trends Ecol Evol 5:159-164

Field JG, Clarke KR, Warwick RM (1982) A practical strategy for analysing multispecies distribution patterns. Mar Ecol Prog Ser 8:37-52

Garrigue $C$ (1995) Macrophyte associations on the soft-bottoms of the south-west lagoon of New Caledonia: description, structure and biomass. Bot Mar 38:481-492

Gaston KJ (1991) How large is a species' geographic range? Oikos 61:434-438

Gaston KJ (1994) Rarity. Chapman and Hall, London

Gaston KJ, Blackburn TM, Gregory RD (1997a) Interspecific abundance-range size relationships: range position and phylogeny. Ecography 20(4):390-399

Gaston KJ, Blackburn TM, Lawton JH (1997b) Interspecific abundance-range size relationships: an appraisal of jnechanisms. J Anim Ecol 66:579-601

Gentry AH (1992) Tropical forest biodiversity: distribution patterns and therr conservation significance. Olkos 63 $19-28$

Gray JS (1997) Marine biodiversity: patterns, threats and conservation needs. Biodiv Conserv 6:153-175

Grime JP (1997) Biodiversity and ecosystem function: the debate deepens. Science 277:1260-1261

Hansen JA, Alongi DM, Moriarty DJW, Pollard PC (1987) The dynamics of benthic microbial communities on Davis Reef, central Great Barrier Reef. Coral Reefs 6:63-70

Hansen JA, Klumpp IDW, Alongi DM, Dayton OK, Riddle MJ (1992) Detrital pathways in a coral reef lagoon. II. Detritus deposition, benthic microbial biomass and production. Mar Biol 113:363-372

Hanski I (1991) Single-species metapopulation dynamics: concepts, models and observations. Biol J Linn Soc 42 : $17-38$ 
Hanski I, Kouki J, Halkka A (1993) Three explanations of the positive relationship between distribution and abundance of species. In: Ricklefs R, Schluter D (eds) Historical and geographic determinants of community diversity. Chicago University Press, Chicago, p 108-116

Hatcher BG (1997) Coral reef ecosystems: how much greater is the whole than the sum of the parts. Coral Reefs 16:77-91

Hill MO (1973) Diversity and evenness: a unifying notation and its consequences. Ecology 54:427-31

Hooper DU, Vitousek PM (1997) The effects of plant composition and diversity on ecosystem processes. Science 277 : $1302-1305$

Jennings $S$, Polunin NVC (1995) Comparative size and composition of yield from six Fijian reef fisheries. J Fish Biol 46:28-46

Kerr JT (1997) Species richness, endemism, and the choice of areas for conservation. Conserv Biol 11:1094-1100

Lacy RC, Bock CE (1986) The correlation between range size and local abundance of some North American birds. Ecology 67:258-260

Lawton JH, Prendergast JR, Eversham BC (1994) The numbers and spatial distribution of species: analysis of British data. In. Forey PL, Humphries CJ, Vane-Wright RI (eds) Systematics and conservation evaluation. Clarendon Press, Oxford, p 177-194

Ludwig JA, Reynolds JF (1988) Statistical ecology. John Wiley, New York

Lundin CG, Lindén O (1993) Coastal ecosystems: attempts to manage a threatened resource. Ambio 22:468-472

Magurran AE (1988) Ecological diversity and its measurement. Croom Helm Ltd, London

McAllister DE, Schueler FW, Roberts CM, Hawkins JP (1994) Mapping and GIS analysis of the global distribution of coral reef fishes on an equal-area grid. In: Miller RI (ed) Mapping the diversity of nature. Chapman \& Hall, London, p 155-175

Mittermeier RA, Myers N, Thomsen JB, da Fonseca GAB, Olivieri S (1998) Biodiversity hotspots and major tropical wilderness areas: approaches to setting conservation priorities. Conserv Biol 12:516-520

Norton BG, Ulanowicz RE (1992) Scale and biodiversity policy: a hierarchical approach. Ambio 21:244-249

Peterson G, Allen CR, Holling CS (1998) Ecological resilience, biodiversity and scale. Ecosystems 1:6-18

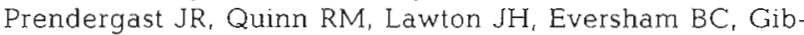
bons DW (1993) Rare species, the coincidence of diversity hotspots and conservation strategies. Nature 365:335-337

Editorial responsibility: Charles Birkeland (Contributing Editor), Mangilao, Guam
Rabinowitz D (1981) Seven forms of rarity. In: Synge $H$ (ed) The biological aspects of rare plant conservation. Wiley, Chichester, p 205-217

Reaka-Kudla ML (1996) The global biodiversity of coral reefs: a comparison with rain forests. In: Reaka-Kudla ML, Wilson DE, Wilson EO (eds) Biodiversity II. Joseph Henry Press, Washington, p 83-108

Reid WV (1998) Biodiversity hotspots. Trends Ecol Evol 13: $275-280$

Riddle MJ, Alongi DM, Dayton PK, Hansen JA, Klumpp DW (1990) Detrital pathways in a coral reef lagoon. I. Macrofaunal biomass and estimates of production. Mar Biol 104: $109-118$

Samuels CL, Drake JA (1997) Divergent perspectives on community convergence. Trends Ecol Evol 12:427-432

Sanderson WG (1996) Rarity of marine benthic species in Great Britain: development and application of assessment criteria. Aquat Cons Mar Freshw Syst 6:245-256

Schlacher TA, Wooldridge TH (1996a) How sieve mesh size affects sample estimates of estuarine benthic macrofauna. J Exp Mar Biol Ecol 201:159-171

Schlacher TA, Wooldridge TH (1996b) Axial zonation patterns of subtidal macrozoobenthos in the Gamtoos estuary, South Africa. Estuaries 19:680-696

Schlacher TA, Wooldridge TH (1996c) Ecological responses to reductions in freshwater supply-lessons for management and conservation of South Africa's estuaries. J Coast Cons 2:115-130

Sisk TD, Launer AE, Switky KR, Ehrlich PR (1994) Identifying extinction threats: global analyses of the distribution of biodiversity and the expansion of the human enterprise. Bioscience 44:592-602

Smith TB, Bruford MW, Wayne RK (1993) The preservation of process: the missing element of conservation programs. Biodiv Lett 1:164-167

Snelgrove PVR, Blackburn TH, Hutchings PA, Alongi DM, Grassle JF, Hummel H, King G, Koike I, Lambshead PJD, Ramsing NB, Sollis-Weiss $V$ (1997) The importance of manine sediment biodiversity in ecosystem processes. Ambio 26:578-583

Tilman D, Knops $J$, Wedin D, Reich P, Ritchie M, Siemann $E$ (1997) The influence of functional diversity and composition on ecosystem processes. Science 277 : $1300-1302$

Wardle DA, Zackrisson O, Hörnberg G, Gallet C (1997) The influence of island area on ecosystem properties. Science $277: 1296-1299$

Submitted: March 5, 1998; Accepted: July 29, 1998 Proofs received from author(s): November 9, 1998 